\title{
The effectiveness of narrative therapy on sexual function and couple burnout
}

A eficácia da terapia narrativa na função sexual e burnout do casal

\author{
Kolsoom Fallah (1) \\ Maryam Ghodsi (2) \\ (1) Islamic Azad University of Semnan, Department of Clinical Psychology, Iran \\ (2) Bojnourd University, Department of Family counseling, Iran
}

\begin{abstract}
Objective: This study aimed to evaluate the effectiveness of narrative therapy on sexual function and couple burnout in women with skin cancer. Method: The research method was quasi-experimental with a pre-test-post-test design with a control group. Among married women with skin cancer in Mashhad (Iran), 30 available individuals were selected and randomly assigned to experimental and control groups. Narrative therapy was performed in a group of 15 people in nine sessions (experimental group). The Female Sexual Function Index and Couple Burnout Measure were used to collect pre-test and post-test data. Analysis of covariance was used to analyze the data. Results: Group narrative therapy significantly improved reported sexual function $(F=40.90 ; p=.001)$ and decreased couple burnout $(F=59.03 ; p=.001)$ in women with skin cancer. Conclusions: Narrative therapy seems to effectively improve sexual function and couple burnout in women with skin cancer.
\end{abstract}

Keywords: Narrative therapy; Sexual function; Couple burnout; Skin cancer; Quasi-experimental design.

\section{DI\&D | ISMT}

rpics@ismt.pt

https://rpics.ismt.pt
Maryam Ghodsi 


\section{Resumo}

Objetivo: Este estudo pretendeu avaliar a eficácia da terapia narrativa sobre a função sexual e o esgotamento do casal em mulheres com cancro de pele. Métodos: O método de investigação foi quase-experimental com desenho pré-testepós-teste com um grupo de controlo. Entre mulheres casadas com cancro de pele em Mashhad (Irão), foram selecionados 30 indivíduos disponíveis e atribuídos aleatoriamente a grupos experimental e de controlo. A terapia narrativa foi realizada num grupo de 15 pessoas em nove sessões (grupo experimental). O Female Sexual Function Index e a Couple Burnout Measure foram utilizados para recolher dados em pré-teste e pós-teste. A análise da covariância foi utilizada para analisar os dados. Resultados: A terapia narrativa grupal melhorou significativamente a função sexual relatada $(F=$ 40,90; $p=0,001)$ e diminuiu o esgotamento do casal $(F=59,03 ; p=0,001)$ em mulheres com cancro de pele. Conclusões: A terapia narrativa parece ser eficaz na melhoria da função sexual e do esgotamento do casal em mulheres com cancro de pele.

Palavras-Chave: Narrativa terapia; Função sexual; Burnout no casal; Cancro de pele; Desenho quase-experimental.

\section{Introduction}

\section{Skin cancer}

Advances in medical science have been considerable in recent years, but cancers have been on the upsurge. Skin cancer is the second most common cancer globally among women (Tagliaferri et al., 2020). Recognizing cancer would be a disturbing and unexpected experience for everyone; as people become aware of a lifethreatening malignancy, their conceptions of life would change. According to research, there is a close relationship between cancer and psychological states (Nipp et al., 2017). Even though cancer causes numerous psychological complications, it has recently been demonstrated that stress significantly impacts the progression of various types of malignant tumors; without actually creating or constructing them (Brinker et al., 2018). Cancer may cause multiple changes, pressures, and effects on the patient's and their family's lives. Recognizing cancer would be a disturbing and unexpected experience for everyone; as people become aware of a lifethreatening malignancy, their conceptions of life would change. In fact, according to research, there is a close relationship between cancer and psychological states (Nipp et al., 2017). Reactions against cancer would be affected by the patient's psychological structure, family, and social environment, and it can impact all levels of the patient's activities (Nipp et al., 2017). Cancer crises could cause mental, physical, and emotional imbalances and inconsistencies (Leiter et al., 2019). Skin cancer is one of the most common types of malignant cancers in the body, with melanoma and non-melanoma the two most prevalent types (LeBoeuf \& Larocca, 2018). There are two major types of non-melanoma skin cancer: basal cell carcinoma (BCC) and squamous cell carcinoma (SCC) (Liu-Smith et al., 2017). Non-melanoma skin cancer is the most common malignancy among whites worldwide, and the prevalence of BCC is approximately 3 to 4 times that of SCC (Albert et al., 2019). According to WHO statistics, between 2 and 3 million cases of this type of skin cancer occur worldwide each year, and this cancer accounts for 30\% of all cancers (Dorj et al., 2018). This painful disease is rather physically and emotionally costly, and patients with this type of cancer frequently suffer from various psychological issues resulting from physical changes (Ghasemzadeh et al., 2017). These issues, which have been related to the patient's factors, treatment-related factors, and other psychosocial factors, could weaken the patient's 
immunity, exacerbate the secondary reactions of treatment, and cause recurrence of the disease (Albert et al., 2019).

\section{Sexual function}

Because chronic conditions impair the affected people and significantly influence their personal and marital lives, they cause tensions and significant distress in the patient's intimate partners. These conditions impair sexual function and undermine the couple's relationship (Fotohi et al., 2018). Sexual function is a part of human life and behavior, and it is so intertwined with a person's personality that it appears impossible to discuss it as a separate phenomenon (Allen \& Walter, 2018). Sexual preferences have always been the focus of human attention, interest, and curiosity, and they have an undeniable impact on a person's marital relationship with his or her sexual partner (Coffelt \& Hess 2014; Hatfield \& Sprecher, 1995). Healthy sexual relations and being aware of couples' sexual relations contribute to the health of men and women in married life, and their sexual intimacy and complexity in married life strengthens relationships and prevents couple burnout (Assali et al., 2015). Men and women's sexual intimacy and complexity in married life strengthens relationships and prevents couple burnout (Assali et al., 2015). As a result, skin cancer in women leads to impaired sexual function and sexual self-esteem. Sexual activities in humans are very important to them, in addition to being instinctive, and over time, they have brought with them religious, mystical, and historical concepts (Collazzoni et al., 2017). Sexual activity has always been one of the most vital aspects of people's lives, and it can be influenced by the individual's characteristics, interpersonal relationships, family, social and cultural conditions, environment, couple sexual activity history, physical and mental health, and hormonal status (lasenza, 2020. The strength of a couple's relationship is compromised without having satisfying sex, and one of the most important reasons for the success of married life is the adaptation in sexual relations, or the balance in the amount of sexual desire in women (lasenza, 2020). According to some researchers, the primary cause of many couple burnouts is couples' sexual dissatisfaction (Assali et al., 2015).

\section{Couple burnout}

Couple burnout is associated with lower emotional attachment, enhanced couple indifference, and the replacement of negative emotions with positive emotions, which contains decreased attention to the spouse, emotional alienation, and feelings of discouragement and indifference toward the spouse (Mikolajczak et al., 2018). It is characterized by discouragement and indifference (Mikolajczak et al., 2018). Today, about 50\% of couples experience burnout during their married life (Alsawalqa et al., 2019). Research shows that chronic disease in one member of the couple can lead to the development and occurrence of couple burnout (Shareh et al., 2021). One of the negative and effective aspects of chronic diseases is the creation of problems and disorders in the sexual relationships of couples. In fact, sexual health is one of the most important and influential factors influencing sexual satisfaction, marital relationships, and couple burnout prevention (Pines, 2013). As a result, it can be assumed that the presence of a chronic disease, such as skin cancer, would probably cause dysfunctional sexual beliefs and couple burnout because of possible sexual dysfunction (Asadi et al., 2016).

\section{Narrative Therapy}


Given that sexual function and, as a result, couple burnout are cultural issues, examining individuals' dominant narratives and using a narrative therapy approach may effectively reduce these issues in women with skin cancers. There are two types of sexual narratives in people: those who are aware but are ashamed to accept them and those who hide them from themselves (lasenza, 2020). If sexual narratives only occur in the conscious mind, it is possible to deal with difficult issues logically: trying to think about them as well as talking about them. However, many sexual narratives, particularly those that cause the most harm to people, are so deeply ingrained in the subconscious that people are unaware of them (lasenza, 2020).

Narrative therapy focuses on the interpretations or meanings which people attribute to events and happenings in their lives; besides, it is the process of assisting people in overcoming their problems through therapeutic conversations (Payne, 2007). This process would alter a person's narrative by rewriting some key elements; in fact, treatment would begin with creating a new narrative (Hutto \& Gallagher, 2017; Savickas, 2011). This therapeutic process emphasizes the externalization of the problems and observes problems as a distinct part of the individual (Ryan et al., 2015). This approach enables the individual to prepare to lead a narrative process in which he or she is the main character, as well as to attempt to create a new moment by challenging the dominant voice that indicates a problem in the individual's narrative (Ribeiro et al., 2016). Narrative counselors are trained not to fall into the trap of general descriptions of a person's identity, particularly when these descriptions define a person in terms of a problem. Narrative therapists assist clients in developing more comprehensive and unique interpretations of themselves and their situations (Payne, 2007). Narrative therapy holds that people use narratives to give meaning to their lives and experiences. The existence of problematic narratives causes problems, and psychological changes and problem-solving are possible due to changing problematic narratives (Ghodsi et al., 2018).

Regarding couples treatment, narrative therapy seeks to uncover narratives that shape the relationship between couples in married life. It also aims to make the process of participatory rewriting of their problematic narratives easier (Vedovo et al., 2020). Encouraging couples to write their own stories can inform them of the dominant culture in their narratives and prepare the couple to choose, change, or preserve the meanings of their married life stories while understanding the other person's language can help couples improve intimate relationships (Ghodsi et al., 2018). Couples expressing and coping with dysfunctional past narratives are more likely to cope with current life events (Ghodsi et al., 2018). In a circumstance in which a woman has skin cancer, and the dominant narrative of her life is that she no longer has the attractiveness of the past due to a change in her appearance and that she is unable to have a good sexual function; that circumstance gradually leads to couple burnout. Given the high levels of cancer spread and its impact on occupational, educational, and family functioning, as well as the resulting psychiatric disorders, and also the costs to the country's health system and economy; we decided to investigate the effect of changes in individual narrations on sexual function and couple burnout in this study. Therefore, the present study was conducted to investigate the effect of narrative therapy on sexual function and couple burnout in women with skin cancer. 


\section{Methods}

\section{Participants and Procedures}

The current study employed a quasi-experimental pre-test-post-test design with a control group. The study's statistical population included all married women referred to Imam Reza and Ghaem hospitals in Mashhad, Iran, in 2021. The sample included 30 volunteers chosen based on inclusion criteria and randomly assigned to experimental and control groups (15 people each). Having at least a diploma, having one type of skin cancer, at least a year has passed since they lived together, and consciously signing a written consent to participate in the research were among the criteria for entering the study. Exclusion criteria included suffering from psychological and personality disorders according to DSM-5 criteria, use of psychiatric and psychotropic drugs in three months before the first session, receiving psychological services and counseling related to marital issues in the last three months, and obvious risk of suicide was present. To adhere to ethical principles, after explaining the project's goals, the confidentiality of the information and voluntary participation in treatment sessions were mentioned. Participants in the experimental groups took part in treatment sessions led by a senior family counseling expert with experience performing therapeutic narratives, while participants in the control group were only asked to take the pre-test and post-test. The participants in the experimental group received the narrative therapy protocol as a group in nine sessions of 90 minutes per week. An independent assessor applied the assessment instruments in pre-test and post-test to all participants in the experimental and control groups, and the control group was assured that they were on the waiting list for treatment and would be treated after the treatment of the experimental group. Table 1 summarizes the content of narrative therapy sessions. The data was analyzed using the SPSS-24 software's multivariate analysis of covariance (MANCOVA) test.

\section{Instruments}

\section{Female Sexual Function Index (FSFI)}

The FSFI was developed by Rosen et al. (2000) to assess female sexual performance. This scale has 19 items and measures six dimensions of women's sexual disorders, including "sexual desire", "sexual hydration", "sexual arousal", "sexual satisfaction", "sexual orgasm", and "sexual pain". The first two items of this questionnaire are scored on a 5-point Likert scale ( 1 to 5 ) and the remaining items on a six-point Likert scale (0 to 5). This questionnaire has a minimum score of 2 and a maximum score of 95 . The reliability coefficient for each of the above areas was between 0.73 and 0.86 , and the internal validity was in the acceptable range ( 0.72 to 0.9 ) (Fakhri et al., 2012). In our study, Cronbach's alpha varied between 0.72 and 0.76 .

\section{Couple Burnout Measure (CBM)}

The CBM is a 20-item self-assessment tool designed to measure the degree of couple burnout among couples (Pines, 2013). The CBM has three main components, namely "physical fatigue" (e.g., feeling tired, lethargic, and having sleep disorders), "emotional exhaustion" (feelings of depression, hopelessness, being trapped), and "mental exhaustion" (such as feelings of worthlessness, frustration, and anger at one's spouse). Items are answered on a seven-point Likert scale (never $=1$ and always $=7$ ). A higher score indicates a higher degree of burnout. CBM presented test-retest reliability of 0.89 for a one-month period, 0.76 for a two-month period, and 0.66 for a four- 
month period, and internal consistency measured through Cronbach's coefficient ranged from 0.91 to 0.93 for its components (Pines, 2013). In Iran, Cronbach's alpha of global CBM with 240 individuals (120 nurses and 120 teachers) was 0.86 (Fatemeh, 2005). Cronbach's alpha in our study was 0.74 .

\section{Client Satisfaction Questionnaire (CSQ)}

Larsen et al. (1979) developed CSQ to assess clients' satisfaction with the services provided during treatment. Each question has four answers, and each answer receives a score between 4 and 1 ( 4 = very positive, $3=$ positive, 2 = negative, very negative $=1$ ) based on its degree of positivity or negativity. The minimum and maximum scores on this scale are 8 (lowest positivity or less satisfaction with the treatment) and 32 (higher satisfaction with the treatment). A previous study confirmed the questionnaire's reliability and validity (0.80) (Vázquez et al., 2019). CSQ presented a Cronbach's alpha of 0.69 in our study.

\section{Clinical Global Impressions (CGI)}

The CGI is the second subscale of the client's global impressions of treatment questionnaire designed by Guy (1979) and is completed at the end of treatment and follow-up by the client to measure the response to treatment. The one-item CGI has a seven-point Likert scale (1 to 7); thus, the minimum and maximum scores on this scale are 1 (more improvement) and 7 (less improvement), respectively. Clinical psychologists and psychiatrists confirmed the content validity of this scale, and its reliability was obtained in a sample of 23 patients with obsessive-compulsive disorder with a one-week retest coefficient of 0.91 (Shareh, 2019).

\section{Narrative Therapy Process}

Sessions of the narrative therapy are presented in Table 1.

\section{Results}

In the present study, 30 women with skin cancer were divided in two groups of 15 experimental (15 women) and control (15 women). The mean age of the experimental group was 28.67 (SD = 3.42), and the control group was $29.61(S D=4.29$ ). Mean and standard deviation of the main research variables are given in Table 2 . KolmogorovSmirnov test showed that the distribution of all variables in both groups was normal $(Z=0.21, p=0.064 ; Z=0.18$, $p=0.19$ for couples' burnout in the control and experimental groups, respectively; $Z=0.13, p=0.20$ and $Z=0.21$, $p=0.08$ for sexual function in the control and experimental groups, respectively). Leven test showed similarity of error variances in couple burnout $(F=1.09, p=0.306)$ and sexual function $(F=1.54, p=0.224)$. The results of the Box test also showed homogeneity of the variance-covariance matrix ( $F=1.83, p=0.052)$. The multivariate analysis of covariance (Pillai's effect: $F=95.08, p=0.001$ ) showed a difference between experimental and control groups.

Table 3 presents the results of the analysis of covariance to determine the effect of narrative therapy on each of the variables (couple burnout and sexual function). Narrative therapy led to a decrease in couple burnout ( $F=$ 59.03, $\left.p=0.001, \eta_{p}^{2}=0.69\right)$ and an increase in sexual function $\left(F=40.9, p=0.001, \eta_{p}^{2}=0.6\right)$. Table 2 shows that after narrative therapy, the experimental group's scores improved in couple burnout (from 4.68 to 4.22 ) and sexual function (from 32.07 to 35.05 ).

\section{Table 1}




\section{\# Session \& Goal}

1 Introducing and expressing the fundamental rules of counseling sessions, such as regular attendance at scheduled times, homework completion, and the principle of confidentiality. Inquire about the person's motivation for attending treatment sessions.

2 Adequate description of the treatment's values, goals, and content, creating a participatory situation in treatment and focusing on clients, attempting to educate clients on how to recognize personal narratives, encourage the person to describe their narratives, pay close attention to the details of the client's language in order to more accurately identify the person's dominant discourse, empathize with the person, and jointly name the problem based on priority over words and client language as a prelude to separating the person from the problem.

3 Reviewing the subject's narration of life, paying close attention to the language and words and metaphors of the references, using extrapolation language and separating the problem from the identity and communication of the references, re-examining the narration expressed by the subject.

4 Expressing significant life events, questioning the narrative, and describing how the problem has disrupted the client's life Examining a person's past or present, interpersonal relationships, and identifying significant and influential people in a person's life who have played significant roles in the course of his or her life story. It also includes giving the individual an explanatory perspective outside of the problem, referencing short narratives, and externalizing the problem (distinguishing between themselves and the problem). Clarify his/her ideas and reactions to problems by taking cultural and social issues into account.

5 Deconstructing and naming problems, deconstructing problematic narratives, reinterpreting or labeling new alternative and preferred narratives, assisting clients in developing awareness, power, a sense of personal agency, and hope through discussion of unique consequences, and encouraging behaviors. In contrast to the narrative, the interval between sessions is riddled with problems. Reading books and content related to the problem is recommended.

6 When the authorities are not under pressure, ask clients about exceptions and unique cases, focusing on the details of the feelings, thoughts, and behaviors of these unique cases, and extending the unique cases to the present. When making exceptions, it is critical to pay attention to one's feelings, behaviors, and thoughts.

7 Share your story, talk about substantial people in your life who have died, and now to remind you of unresolved issues. Designing abilities include: 1) Communication skills: expressing thoughts and feelings, creating desires; 2) Listening skills. Requesting that authorities send unsolicited letters, forgive, forget, or release bullies and criminals, as well as others who have already caused authorities to have bad memories. It is then followed by a study of the recommended content.

8 Reconstructing and retelling life's story with fresh terms, analyzing old memories and potential future behaviors, exploring positive events and alternative narratives, retelling and consolidating alternative narratives, and verifying alternative narratives are all examples of alternative narratives. To envision one's future while remaining solid and deserving.

9 Rewriting the narrative of life, examining the new narrative of the person, predicting possible problems, final editing of the new narrative, playing a role in the new narrative of your life. Much of the work of narrative therapy involves telling and retelling. The treatment ends when the client feels that his or her narrative has changed.

Table 2

Descriptive Analysis of Research Variables by Groups in Pre-test and Post-test

\begin{tabular}{llcccc}
\hline & & \multicolumn{2}{c}{ Pre-test } & \multicolumn{2}{c}{ Post-test } \\
\cline { 2 - 6 } Variables & Groups & $M$ & $S D$ & $M$ & $S D$ \\
\hline \multirow{2}{*}{ Couple burnout } & Experimental & 4.68 & 0.11 & 4.22 & 0.38 \\
& Control & 4.69 & 0.22 & 4.67 & 0.21 \\
\hline \multirow{2}{*}{ Sexual function } & Experimental & 32.07 & 6.04 & 35.05 & 6.41 \\
& Control & 32.53 & 4.36 & 32.87 & 4.82 \\
\hline
\end{tabular}

Note. $N=30$. Each group had 15 women. 


\section{Table 3}

Univariate Analysis of Covariance for Narrative Therapy on Couple Burnout and Sexual Function

\begin{tabular}{lcccccc}
\hline Variable & SS & $d f$ & $M S$ & $F$ & $p$ & $\eta_{p}^{2}$ \\
\hline Couple burnout & 1.06 & 1 & 1.06 & 59.03 & 0.001 & 0.69 \\
Sexual function & 51.56 & 1 & 51.56 & 40.91 & 0.001 & 0.59 \\
\hline
\end{tabular}

Note. $N=30 . S S=$ Type III Sum of Squares effect; $M S=$ Mean square effect.

The CSQ and CGI questionnaires were used to determine the degree of satisfaction and feeling of progress among the experimental group participants, and the findings are summarized in Table 4. The subjects were highly pleased with the therapeutical process, with a mean overall score of $24.81(S D=2.36)$. A score of 1 on the client Clinical Global Impressions scale (CGI) means that the subjects have improved due to the therapy. Clients report more recovery the higher the subject's score is to one; the closer it gets to seven, the less and worse the recovery rate from treatment. The average total improvement of clients was $2.33(S D=0.97)$.

\section{Table 4}

General Satisfaction and Improvement of Women after Treatment

\begin{tabular}{lcccc}
\hline Level of recovery & Lowest score & Highest score & $M$ & $S D$ \\
\hline Satisfaction (CSQ) & 21 & 29 & 24.81 & 2.36 \\
Improvement (CGI) & 1 & 4 & 2.33 & 0.97 \\
\hline
\end{tabular}

Note. $N=15$. CSQ = Client Satisfaction Questionnaire. $C G I=$ Clinical Global Impressions.

\section{Discussion}

According to the results of this research, the narrative therapy approach decreased couple burnout and improved sexual function in women with skin cancer. Research background in this field was very limited. However, the findings of this study are consistent with Fotohi et al.'s (2015) research on the efficacy of psychotherapy in treating couple burnout. Couples who have a better understanding and knowledge of sex in marriage will be able to adjust and develop their relationship methods and find positive solutions to marital disputes (Asadpour \& Veisi, 2017).

Narrative therapy (lasenza, 2020), for example, is one of the strategies that are successful in minimizing the disparity in sexual desire and can be used to address the emotional and sexual issues of couples. The couple's inattention causes couple burnout to each other's needs. Couple burnout spreads when partners have irrational and unrealistic expectations (Pines et al., 2011). According to Martínez-Martínez et al. (2017), increasing emotional intimacy strengthens sexual relationships in women who view sexual function as a negative act. As a result, narrative therapy aims to reconstruct the underlying desires and self-supporting responses in interactions 
by assisting partners in accessing the life narratives that control their lives, thus removing the negative perception of sex.

During the treatment process, women receive improved evaluations of their vulnerability to stressful events such as skin abnormalities; as a result, they respond better to various circumstances and use more successful coping strategies. Narrative therapy is effective in improving marital relationships because it enables people to identify their narratives, the impact of others and societal culture on these narratives, and comprehend how old narratives influence their behavior. As a result, they understand what is causing the current relationship to deteriorate. In fact, one learns to narrate life in a way that helps to improve effective communication with a partner or family member. By changing these initial narratives, narrative therapy allows a woman to accept herself and that the problem is the problem, not the person; to not accept skin cancer as a part of herself, instead, accept it as a problem for which a cure can be found.

Renaming and rewriting life stories is a way to solve marital problems and avoid relationship burnout. Attending narrative therapy sessions helps people define problems as solvable by changing the prevailing negative narratives and externalizing them by asking unique questions and results ("Haven't I had the opportunity to enjoy a marital relationship despite my new appearance?"; "Since when did I let skin cancer take over my life?"). The main purpose of such therapy is to increase one's understanding of narratives taken from the culture in order to better grasp the inconsistencies between the problematic stories from the past and the recent stories that have made a distinction (Fernández-Navarro et al., 2018).

Problem externalization, as a primary process in narrative therapy, facilitates the separation between the individual and the problem (skin cancer), and by relying on the abilities, beliefs, and competencies of individuals, can reduce the influence of problems and define problems as flexible and solvable (Ryan et al., 2015). Clients can remember occasions when they did not have issues with skin cancer in their marital relationship with their partner. If they did, the seriousness of those problems was very mild; by finding exceptions in therapy sessions using the exception questioning technique, making exceptions allowed clients to find out what their marital relationship was like in those circumstances and what they did and still do.

Narrative therapy enables people to talk to their spouses about the problematic stories that have shaped current issues. By listening to each other's life stories, they form deeper emotional relationships. This causes the couple to participate in creating positively themed narratives, creating new experiences and behaviors. By writing his narrations, they can become aware of the dominant story culture, in which the decline of sexual function due to changes in skin and appearance is considered natural, and realize their power to choose, alter, or edit the stories of their married lives. Life storytelling may aid in selecting successful marital solutions; the ability to write has a significant impact on promoting storytelling, the ability to construct meaningful life stories, the creation of emerging narrative, and the facilitation of change in adolescents (Ricks et al., 2014).

People discover their capacities and abilities by using introductory rituals in meetings. This discovery not only changes one's view of them, but it also shows others how one thinks of themselves and influences the mindset of those around them (Payne, 2007). The narrative of sex therapists considers that it is essential to develop a keener understanding of gender, including family, social, historical, and psychological effects; to improve sexual 
function; therefore, it is important to understand the meaning of different sexual experiences in a person's specific cultural background through sexual history (lasenza, 2020).

The sex menu was the next most effective method to help people shift their false and negative sexual narratives. It enables clients to be conscious of their sexual orientation, desires, and desired experiences with their partners (lasenza, 2020). This allows couples to talk freely and frankly about their sexual preferences and needs. When selecting a sex menu, the first step is to encourage clients to think of themselves as sexual beings, rather than limiting their relationships to the same fixed framework, and to plan their menu in such a way that skin and appearance changes are kept to a minimum.

\section{Limitations}

Due to the limited availability of scientific and study tools on sexual function and couple burnout in women with skin cancer, and the lack of follow-up, generalizing the findings should be done with caution.

The effect of environmental and cultural factors on the perception of this population of women about treatment as well as other problems of the subjects that can affect the effectiveness of treatment is another limitation of the present study.

Besides, limited access to women with cancer due to the prevalence of coronavirus and general quarantine is another limitation of the present study. It is suggested that the effectiveness of the narrative-therapy approach on sexual function and couple burnout along with follow-up and comparison with other therapeutic approaches in different populations to determine the reliability of the effects.

Because the survival rate of people with skin cancer is improving due to advances in diagnostic and therapeutic methods, there is a strong need to take measures to control the psychological effects of the disease and assess their sexual function and couple burnout. Given the study's findings on the effectiveness of the narrative-therapy approach on the research components, it is suggested that the narrative approach be used in counseling centers to assist couples in reducing marital conflicts, teaching communication issues, and familiarizing them with sexual needs.

\section{Conclusion}

According to the current study's findings, narrative therapy could improve sexual function and reduce couple burnout among women with skin cancer. The narrative therapy approach assisted experimental group members in sharing their problems in the group, receiving effective coping strategies from group members, and re-framing and writing new narratives of their lives. According to the findings of the study, the outcomes of working with couples, families, and women with skin cancer would probably be used in health centers, counseling centers, welfare centers, and pre-divorce counseling in the judiciary; the findings of this study can be beneficial for individuals and couples who present with couple burnout and sexual dissatisfaction.

Conflict of interest | Conflito de interesse: The authors do not have any conflict of interests | Os autores declaram não ter conflitos de interesse.

Funding sources | Fontes de financiamento: Not applicable | Não se aplica.

Contributos: KF: Literature review; Data collection and analysis MG: Writing manuscript draft and final manuscript. 


\section{References}

Albert, A., Knoll, M. A., Conti, J. A., \& Zbar, R. I. S. (2019). Non-melanoma skin cancers in the older patient. Current Oncology Reports, 21(9), Article 79. https://doi.org/10.1007/s11912-019-0828-9

Allen, M. S., \& Walter, E. E. (2018). Linking big five personality traits to sexuality and sexual health: A metaanalytic review. Psychological Bulletin, 144(10), 1081-1110. https://doi.org/gdnbtj

Alsawalqa, R. O. (2019). Marriage burnout: When the emotions exhausted quietly quantitative research. Iranian Journal of Psychiatry and Behavioral Sciences, 13(2), Article 2. https://doi.org/10.5812/ijpbs.68833

Asadi, E., Mansour, L., Khodabakhshi, A., Fathabadi, J. (2016). The relationship between couple burnout, sexual assertiveness, and sexual dysfunctional beliefs in women with diabetic husbands and comparing them with women with non-diabetic husbands. Journal of Family Research, 9(3), 311-324. https://bit.ly/34N5vgx

Asadpour, E., \& Veisi, S. (2017). The effectiveness of emotionally focused couple therapy on sexual self-esteem and sexual function in women with multiple sclerosis. Journal of Arak University of Medical Sciences, 20(7), 112. http://jams.arakmu.ac.ir/article-1-5174-en.html

Assali, R., Jalal Marvi, F., Ansari, F., \& Lashkardost, H. (2015). Premenstrual syndrome and the marital relationship. Journal of North Khorasan University of Medical Sciences, 7(2), 465-473. https://doi.org/10.29252/jnkums.7.2.465

Brinker, T. J., Hekler, A., Utikal, J. S., Grabe, N., Schadendorf, D., Klode, J., Berking, C., Steeb, T., Enk, A. H., \& Kalle, C. von. (2018). Skin Cancer Classification Using Convolutional Neural Networks: Systematic Review. Journal of Medical Internet Research, 20(10), Article e11936. https://doi.org/10.2196/11936

Coffelt, T. A., \& Hess, J. A. (2014). Sexual disclosures: Connections to relational satisfaction and closeness. Journal of Sex \& Marital Therapy, 40(6), 577-591. https://doi.org/g9h6

Collazzoni, A., Ciocca, G., Limoncin, E., Marucci, C., Mollaioli, D., Di Sante, S., Di Lorenzo, G., Niolu, C., Siracusano, A., Maggi, M., Castellini, G., Rossi, A., \& Jannini, E. A. (2017). Mating strategies and sexual functioning in personality disorders: A comprehensive review of literature. Sexual Medicine Reviews, 5(4), 414-428. https://doi.org/gf99hs

Dorj, U.-O., Lee, K.-K., Choi, J.-Y., \& Lee, M. (2018). The skin cancer classification using deep convolutional neural network. Multimedia Tools and Applications, 77(8), 9909-9924. https://doi.org/10.1007/s11042018-5714-1

Fakhri, A., Pakpour, A. H., Burri, A., Morshedi, H., \& Zeidi, I. M. (2012). The Female Sexual Function Index: Translation and validation of an Iranian version. The Journal of Sexual Medicine, 9(2), 514-523. https://doi.org/cgpds2

Fatemeh, N. (2005). Investigating and comparing the relationship between marital boredom and organizational climate factors in employees of education departments and nurses in Tehran hospitals [Unpublished master's thesis]. Shahid Beheshti University.

Fernández-Navarro, P., Rosa, C., Sousa, I., Moutinho, V., Antunes, A., Magalhães, C., Ribeiro, A. P., \& Gonçalves, M. M. (2018). Reconceptualization innovative moments as a predictor of symptomatology improvement in treatment for depression. Clinical Psychology \& Psychotherapy, 25(6), 765-773. https://doi.org/10.1002/cpp.2306

Fotohi, S., Mikaeili, N., Atadokht, A., \& Hajlo, N. (2018). Comparing the effectiveness of meta- emotion based couple therapy with narrative couple therapy on adjustment and couple burnout in conflicting couples. Counseling Culture and Psychotherapy, 9(34), 77-101. https://doi.org/10.22054/qccpc.2018.27362.1672

Ghasemzadeh, F., Etminani, K., Arab-Kheradmand, A., \& Hosseini Moini, S. B. (2017). A retrospective study on non melanoma skin cancer in Cancer Institute, Imam Khomeini Medical Center, Tehran, Iran. Journal of Dermatology and Cosmetic, 8(1), 9-21. http://jdc.tums.ac.ir/article-1-5231-en.html

Ghodsi, M., Barabadi, H. A. B., \& Heydarnia, A. H. (2018). Effectiveness of narrative therapy on reducing divorce tendency and its components in women with early marriage. Counseling Culture and Psychotherapy, 9(33), 73-98. https://doi.org/10.22054/qccpc.2018.28555.1712

Guy, W. (1976). ECDEU assessment manual for psychopharmacology (Rev. 1976.). U.S. Dept. of Health, Education, and Welfare, Public Health Service, Alcohol, Drug Abuse, and Mental Health Administration, National 
Institute of Mental Health, Psychopharmacology Research Branch, Division of Extramural Research Programs.

Hatfield, E., \& Sprecher, S. (1995). Men's and women's preferences in marital partners in the United States, Russia, and Japan. Journal of Cross-Cultural Psychology, 26(6), 728-750. https://doi.org/cm3jm9

Heidari, M., Shahbazi, S., Ghafourifard, M., \& Ali Sheikhi, R. (2017). Prediction of marital satisfaction based on emotional intelligence in postmenopausal women. Journal of Menopausal Medicine, 23(3), $196-201$. https://doi.org/10.6118/jmm.2017.23.3.196

Hutto, D. D., \& Gallagher, S. (2017). Re-Authoring narrative therapy: Improving our self-management tools. Philosophy, Psychiatry, \& Psychology, 24(2), 157-167. https://doi.org/10.1353/ppp.2017.0020

lasenza, S. (2020). Transforming sexual narratives: A relational approach to sex therapy. Routledge.

Larsen, D. L., Attkisson, C. C., Hargreaves, W. A., \& Nguyen, T. D. (1979). Assessment of client/patient satisfaction: Development of a general scale. Evaluation and Program Planning, 2(3), $197-207$. https://doi.org/10.1016/0149-7189(79)90094-6

LeBoeuf, N. R., \& Larocca, C. (2018). Cutaneous malignancy, an issue of hematology/oncology clinics (Vol. 33 , No. 1). Elsevier Health Sciences.

Leiter, U., Keim, U., \& Garbe, C. (2019). Epidemiology of skin cancer: Update 2019. Advances in Experimental Medicine and Biology, 1268, 123-139. https://doi.org/10.1007/978-3-030-46227-7_6

Liu-Smith, F., Jia, J., \& Zheng, Y. (2017). UV-induced molecular signaling differences in melanoma and nonmelanoma skin cancer. In S. Ahmad (Ed.), Ultraviolet light in human health, diseases and environment (Vol. 996, pp. 27-40). Springer, Cham. https://doi.org/ghpsvt

Martínez-Martínez, A., Arnau, J., Salmerón, J. A., Velandrino, A. P., \& Martínez, M. E. (2017). The sexual function of women during puerperium: A qualitative study. Sexual and Relationship Therapy, 32(2), $181-194$. https://doi.org/10.1080/14681994.2016.1263389

Mikolajczak, M., Brianda, M. E., Avalosse, H., \& Roskam, I. (2018). Consequences of parental burnout: Its specific effect on child neglect and violence. Child Abuse \& Neglect, 80, $134-145$. https://doi.org/10.1016/j.chiabu.2018.03.025

Nipp, R. D., El-Jawahri, A., Moran, S. M., D’Arpino, S. M., Johnson, P. C., Lage, D. E., Wong, R. L., Pirl, W. F., Traeger, L., Lennes, I. T., Cashavelly, B. J., Jackson, V. A., Greer, J. A., Ryan, D. P., Hochberg, E. P., \& Temel, J. S. (2017). The relationship between physical and psychological symptoms and health care utilization in hospitalized patients with advanced cancer. Cancer, 123(23), 4720-4727. https://doi.org/gcmvdv

Payne, M. (2007). Narrative therapy: Making meaning, making lives. Sage Publications.

Pines, A. (2013). Couple burnout: Causes and cures. Routledge.

Pines, A. M., \& Nunes, R. (2003). The relationship between career and couple burnout: Implications for career and couple counseling. Journal of Employment Counseling, 40(2), 50-64. https://doi.org/fx3gvc

Pines, A. M., Neal, M. B., Hammer, L. B., \& Icekson, T. (2011). Job Burnout and couple burnout in dual-earner couples in the sandwiched generation. Social Psychology Quarterly, 74(4), 361-386. https://doi.org/dhpbkd

Ribeiro, A. P., Braga, C., Stiles, W. B., Teixeira, P., Gonçalves, M. M., \& Ribeiro, E. (2016). Therapist interventions and client ambivalence in two cases of narrative therapy for depression. Psychotherapy Research: Journal of the Society for Psychotherapy Research, 26(6), 681-693. https://doi.org/g9kt

Ricks, L., Kitchens, S., Goodrich, T., \& Hancock, E. (2014). My story: The use of narrative therapy in individual and group counseling. Journal of Creativity in Mental Health, 9(1), 99-110. https://doi.org/ghfzgc

Ryan, F., O'Dwyer, M., \& Leahy, M. M. (2015). Separating the problem and the person: Insights from narrative therapy with people who stutter. Topics in Language Disorders, 35(3), 267-274. https://doi.org/f785hz

Savickas, M. L. (2011). Constructing careers: Actor, agent, and author. Journal of Employment Counseling, 48(4), 179-181. https://doi.org/fzwbw8

Shareh H. (2019). Validation and investigating the psychometric properties of the client satisfaction questionnaire and client clinical global index in a sample of patients with obsessive-compulsive disorder [Unpublished doctoral dissertation]. Mashhad Ferdowsi University

Shareh, H., Ghodsi, M., \& Keramati, S. (2021). Emotion-focused group therapy among women with premenstrual dysphoric disorder: A randomized clinical trial. Psychotherapy Research: Journal of the Society for Psychotherapy Research, 1-16. Advance online publication. https://doi.org/g9jn 
Tagliaferri, L., Di Stefani, A., Schinzari, G., Fionda, B., Rossi, E., Del Regno, L., Gentileschi, S., Federico, F., Valentini, V., Tortora, G., Peris, K., \& Gemelli Skin-Cancer Multidisciplinary Tumour Board (S-MDTB). (2020). Skin cancer triage and management during COVID-19 pandemic. Journal of the European Academy of Dermatology and Venereology: JEADV, 34(6), 1136-1139. https://doi.org/10.1111/jdv.16529

Vázquez, F. L., Torres, Á., Otero, P., Blanco, V., \& Clifford Attkisson, C. (2019). Psychometric properties of the Castilian Spanish version of the Client Satisfaction Questionnaire (CSQ-8). Current Psychology, 38(3), 829835. https://doi.org/g9kv

Vedovo, F., Di Blas, L., Perin, C., Pavan, N., Zatta, M., Bucci, S., Morelli, G., Cocci, A., Delle Rose, A., Caroassai Grisanti, S., Gentile, G., Colombo, F., Rolle, L., Timpano, M., Verze, P., Spirito, L., Schiralli, F., Bettocchi, C., Garaffa, G., ... Trombetta, C. (2020). Operated Male-to-Female Sexual Function Index: Validity of the first questionnaire developed to assess sexual function after male-to-female gender affirming surgery. The Journal of Urology, 204(1), 115-120. https://doi.org/g9kw 